\title{
25. BETA-SITOSTEROL AND STIGMASTEROL IN SLOPE SEDIMENTS ${ }^{1}$
}

\author{
Joseph A. Curiale ${ }^{2}$ and William E. Harrison, Oklahoma Geological Survey, \\ University of Oklahoma, Norman, Oklahoma
}

\begin{abstract}
Sediments collected from three continental slope sites of Leg 67 have been examined for total organic carbon content and amount of the sterols beta-sitosterol and stigmasterol. The amount of beta-sitosterol relative to stigmasterol is found to increase landward in the sediment, despite differing ages of the samples studied. The ratio of beta-sitosterol to stigmasterol in near-shore sediments is proposed as a source proximity indicator.
\end{abstract}

\section{INTRODUCTION}

Six sediment samples from the continental slope southwest of Guatemala, ranging in age from approximately 0.1 to 3.1 m.y. (von Huene et al., 1980), have been analyzed for sterol indicators of proximity to source environment. The purpose of this study is to establish trends of two sterols in sediments along a $50-\mathrm{km}$ transect perpendicular to the shoreline on a continental slope. Several sites of Leg 67 were uniquely suited for this purpose, because San Jose Canyon, offshore Guatemala, provides an efficient channel by which terrigenous sediment migrates to the Middle America Trench. The organic matter of six samples from three sites has been analyzed for total organic carbon and sterol content. Results indicate trends that correlate to the distance between the site of sediment deposition and the shore.

Two samples each from Sites 496, 497, and 500 were studied. Site and sample information is listed in Table 1.

\section{EXPERIMENTAL PROCEDURE}

Samples were collected immediately after the core was split. The muds were placed in quart-size cans; each can was filled two-thirds full with distilled water, sealed, inverted and kept frozen until samples were received in the laboratory.

Upon receipt in the laboratory, the cans were brought to room temperature, and for future analysis the head gas present was transferred into evacuated gas sampling bulbs using a can puncturing tool. The cans were then refrozen, and the frozen sediment was freezedried.

All glassware used was prerinsed with appropriate solvents; in addition, glassware used in the sterol extractions was acid-washed. All solvents were reagent grade, and were redistilled for laboratory use. All extracts were dried under a nitrogen flow.

The sterol extraction procedures were modified after Huang and Meinschein (1976) as follows: The dry sediment was Soxhlet extracted using 5:1 benzene:methanol. Each dried extract was saponified according to the procedure of Huang and Meinschein (1976). The unsaponified portion was chromatographed on a $30-\mathrm{cm} \times 1.0-\mathrm{cm}$ silica gel column, using 12 grams of silica gel predried at $250^{\circ} \mathrm{C}$ for 3 hours. The material was eluted with $n$-heptane $(100 \mathrm{ml})$, carbon tetrachloride $(100 \mathrm{ml})$, chloroform $(60 \mathrm{ml})$, and methanol $(100 \mathrm{ml})$. The benzene fraction was brought to dryness under nitrogen and dissolved in

\footnotetext{
${ }^{1}$ Aubouin, J., von Huene, R., et al., Init, Repts, DSDP, 67: Washington (U.S. Govt. Printing Office)

2 Present address: Science and Technology Division, Union Oil Company of California, Brea, California.
}

chloroform. Alcohols present in this fraction were converted to the trimethylsilyl (TMS) ether derivatives using $1.0-\mathrm{ml}$ ampules of $\mathrm{N}, \mathrm{O}$ bis (trimethylsilyl) acetamide (BSA), purchased from Supelco, Inc. This fraction was then analyzed for sterol content.

\section{Instrumental Procedures}

Gas chromatographic analyses were carried out on a HewlettPackard 5830A instrument. Instrument conditions are given in Figure 3. The commercially obtained sterols cholesterol, stigmasterol, and beta-sitosterol were reacted with BSA to form TMS derivatives, then used as standards. In addition, gas chromatography-mass spectrometry (GCMS) was used to confirm identifications of TMS-stigmasterol and TMS-beta-sitosterol. This analysis was conducted on a HewlettPackard 5985B GCMS; conditions are listed in Figure 1.

Total organic carbon analyses were carried out using a LECO WR-12 Carbon Analyzer. Duplicate analyses were performed for each sample.

\section{RESULTS AND DISCUSSION}

Table 1 lists total organic carbon (TOC) information for whole sediment. TOC appears to vary systematically with distance from the source of organic detritus, as would be expected.

One sample from each of Sites 496, 497, and 500 was analyzed for sterol content. Specifically, we analyzed for stigmasterol (24-alpha-Ethyl-5,22-cholestadien-3-beta-ol) and beta-sitosterol (24-alpha-Ethyl-5-cholesten-3-betaol), because the GCMS data contain only two strong peaks in the $\mathrm{m} / \mathrm{e}=129$ mass fragmentogram, corresponding to major fragments of the TMS derivatives of stigmasterol and beta-sitosterol (Brooks et al., 1973; Diekman and Djerassi, 1967; Knights, 1967). Final confirmation of the existence of these sterols in the sediment is indicated by Figures 1 and 2. Figure 1 is the total ion current trace of the TMS derivative of the benzene fraction of Sample 3B. Mass spectra obtained from this

Table 1. General sample information.

\begin{tabular}{cccccc}
\hline $\begin{array}{c}\text { Sample } \\
\text { Identification } \\
\text { Number }\end{array}$ & $\begin{array}{c}\text { Sample } \\
\text { (interval in cm) }\end{array}$ & $\begin{array}{c}\text { Sub-bottom } \\
\text { Depth } \\
(\mathrm{m})\end{array}$ & $\begin{array}{c}\text { Seaward Distance } \\
\text { Along Canyon } \\
\text { Axis }(\mathrm{km})\end{array}$ & $\begin{array}{c}\text { Estimated } \\
\text { Agc }^{\mathrm{a}} \\
(\mathrm{m} . \mathrm{y} .)\end{array}$ & $\begin{array}{c}\text { Total Organic } \\
\text { Carbon (\%) }\end{array}$ \\
\hline 1A & $496-3-1,70-90$ & 17.8 & 102 & 0.1 & 2.75 \\
1B & $496-22-1,100-125$ & 198.6 & 102 & 1.5 & 2.29 \\
2A & $497-7-3,40-60$ & 58.0 & 109 & 0.5 & 2.18 \\
2B & $497-34-1,40-60$ & 311.5 & 109 & 3.1 & 2.08 \\
3A & $500-4-1,5-25$ & 23.7 & 149 & 0.4 & 1.51 \\
3B & $500-9-3,60-80$ & 74.7 & 149 & 1.0 & 1.77 \\
\hline
\end{tabular}

a From von Huene et al., 1980 


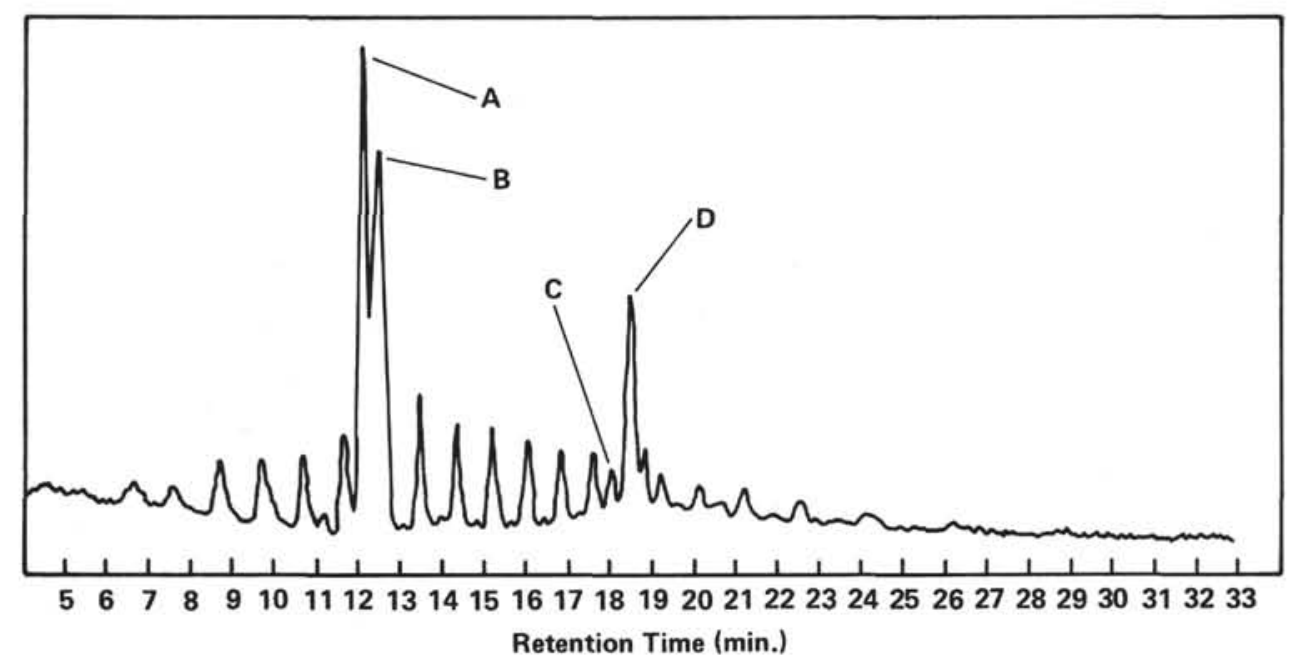

Figure 1. Total ion current trace of Sample 3B. (Mass spectra of Peaks C and D, TMS-stigmasterol and TMS-beta-sitosterol, respectively, are shown in Fig. 2. Mass spectra of Peaks A and B indicate that these are probably TMS derivatives of acids that were not completely saponified. GCMS conditions: 6 ft., $1 \% \mathrm{OV}-17$ column, temperature programmed from $150^{\circ} \mathrm{C}$ [held $1 \mathrm{~min}$.] to $285^{\circ} \mathrm{C}$, at $8^{\circ} \mathrm{C} / \mathrm{min}$. Mass spectra were recorded at $70 \mathrm{eV}$, with a source temperature of $200^{\circ} \mathrm{C}$; recording rate was 15 mass spectra per min.)

GCMS run for TMS-stigmasterol and TMS-beta-sitosterol are presented in Figure 2. The spectra agree with those previously published (e.g., Eneroth et al., 1964).

We have made semiquantitative determinations of the amount of each of these sterols in the sediment, on the basis of the gas-chromatographic response determined by analysis of standard TMS-stigmasterol and TMS-beta-sitosterol. Table 2 presents the amount of these sterols relative to total organic carbon in the sediment. In addition, the total parts of beta-sitosterol + stigmasterol per million parts of organic carbon in each sediment is listed. These yields are within the ranges reported by Schwendinger and Erdman (1964) and Attaway and Parker (1970) for the Gulf of Mexico and offshore southern California (San Pedro Bay), respectively.

Huang and Meinschein $(1976,1979)$ noted that betasitosterol and stigmasterol are common constituents of marine and near-shore sediments. Beta-sitosterol content averaged $15 \%$ of total sterols in Gulf of Mexico sediments, and $37 \%$ of total sterols in fresh-water (river-inlet) sediments. Stigmasterol content in these two environments is $11 \%$ and $19 \%$, respectively. These numbers reflect both original biochemical source input and any early-stage diagenetic changes that these samples have undergone. Data in Table 2 indicate, however, that the diagenetic reduction processes suggested by Gaskell and Eglinton (1973) have probably not been severe in the Leg 67 sediments, because the greatest sterol concentration is found in the oldest sample (2B). Therefore beta-sitosterol and stigmasterol can be useful as source indicators in young sediments.

The ratio of beta-sitosterol to stigmasterol is a useful parameter as a source proximity indicator. This ratio, using data of Huang and Meinschein (1976), is 1.4 for Gulf of Mexico sediments, 1.9 for fresh-water sediments, and 2.3 for sediments at the mouth of the Aransas River in Copano Bay, Texas. This trend indicates an increase in the ratio of beta-sitosterol to stigmasterol with an increasing terrigenous organic component in the sediment. It is instructive to compare these values with those for living organic matter. The ratio averages 2.0 for 12 Gulf and Bay plankton (Huang and Meinschein, 1976) and is greater than 3.7 in the leaves of the higher plant Kalanchoe blossfeldiana (Pryce, 1971), indicating a high ratio for a terrigenous source material and a lower ratio for a marine source material. Therefore, the dilution of near-shore sediment with marine-derived organic matter should result in a decrease in the beta-sitosterol/stigmasterol ratio. The decrease is apparently a function of organic source input rather than of diagenetic processes. The latter would result in in situ reduction of each of the two sterols. However, their structural similarity would imply similar rates of reduction, both being reduced to stigmastanol (Henderson, et al., 1971; Gaskell and Eglinton, 1973). Thus this ratio is affected predominantly by source of organic input.

Systematic changes in this ratio are observed in the present study, as indicated in Figure 3. The ratio decreases with an increase in seaward distance, indicating a steady dilution by marine organic matter and suggesting that the ratio may serve as a reliable source indicator in near-shore sediments. Ultimately, the method has promise as a technique for fixing the position of paleoshorelines.

\section{CONCLUSIONS}

Results of this study indicate that the ratio of betasitosterol to stigmasterol may serve as an indicator of the relative amount of marine organic matter present in near-shore sediments. This ratio is known to be higher in terrestrial organic matter than in marine organic matter. This is reflected in the decrease of beta-sitosterol relative to stigmasterol that one observes as seaward distance increases in Leg 67 slope sediments. 

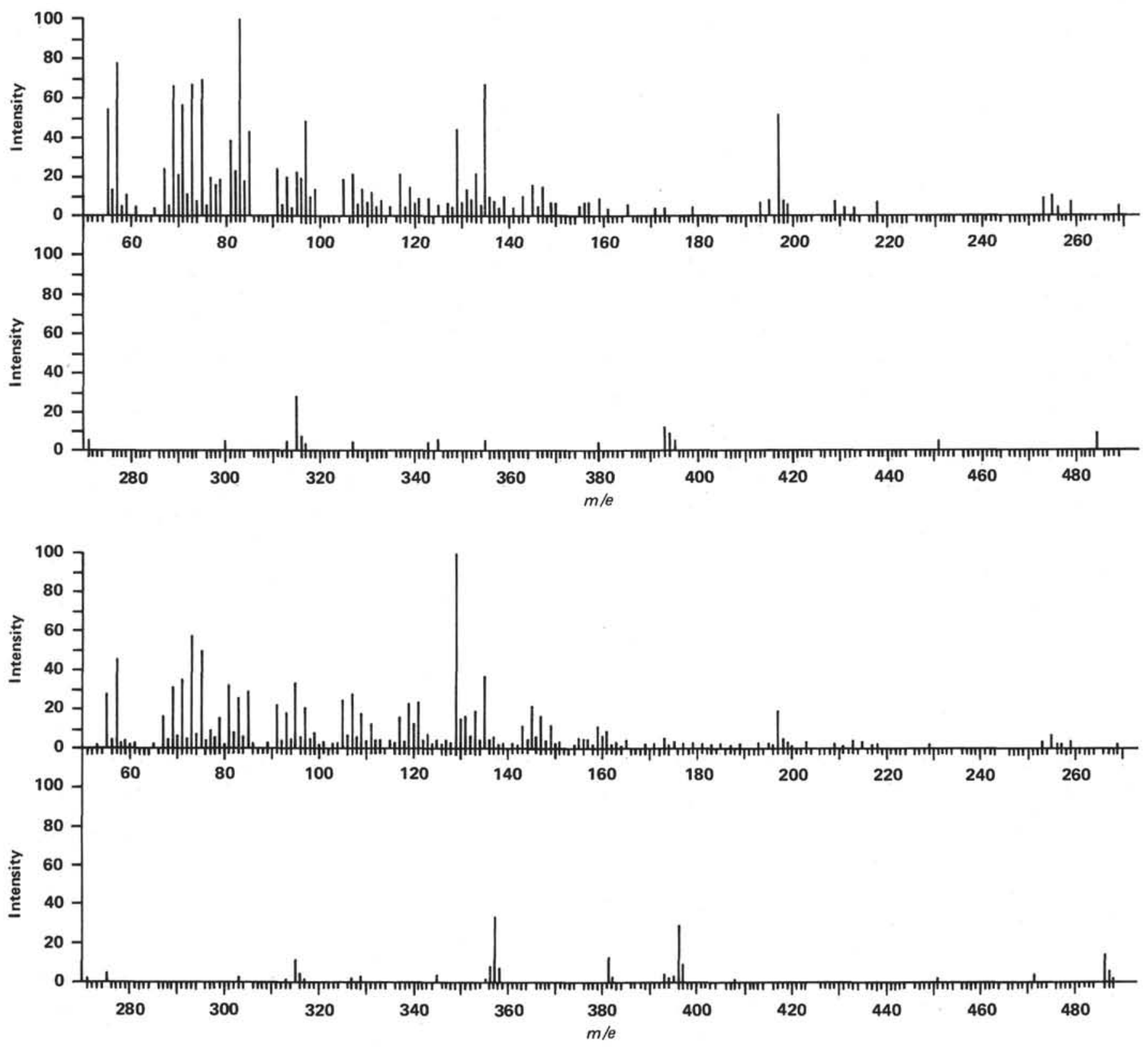

Figure 2. Mass spectra of TMS-stigmasterol (top) and TMS-beta-sitosterol (bottom). (Instrument conditions are as given in Fig. 1.)

Table 2. Sediment sterol content.

\begin{tabular}{|c|c|c|c|c|}
\hline \multirow{3}{*}{$\begin{array}{c}\text { Sample } \\
\text { Identification } \\
\text { Number }\end{array}$} & Stigmasterol & Beta-Sitosterol & $\begin{array}{l}\text { Stigmasterol + } \\
\text { Beta-Sitosterol }\end{array}$ & \multirow{3}{*}{$\frac{\text { Beta-Sitostero }}{\text { Stigmasterol }}$} \\
\hline & TOC & TOC & TOC & \\
\hline & (ppm) & (ppm) & (ppm) & \\
\hline 1B & 7.7 & 19.7 & 27.4 & 2.56 \\
\hline 2B & 57.0 & 102.9 & 159.9 & 1.81 \\
\hline $3 \mathrm{~A}$ & 36.2 & 51.7 & 87.9 & 1.43 \\
\hline
\end{tabular}

\section{ACKNOWLEDGMENTS}

Emre Sancaktar performed the LECO analyses. Robert Carlson of Chevron Oil Field Research Company provided advice on the sterol aspect of this study. The manuscript was reviewed by L. S. Ciereszko of the Department of Chemistry, University of Oklahoma, and W. G. Meinschein of the Department of Geology, University of Indiana; their comments were greatly appreciated.

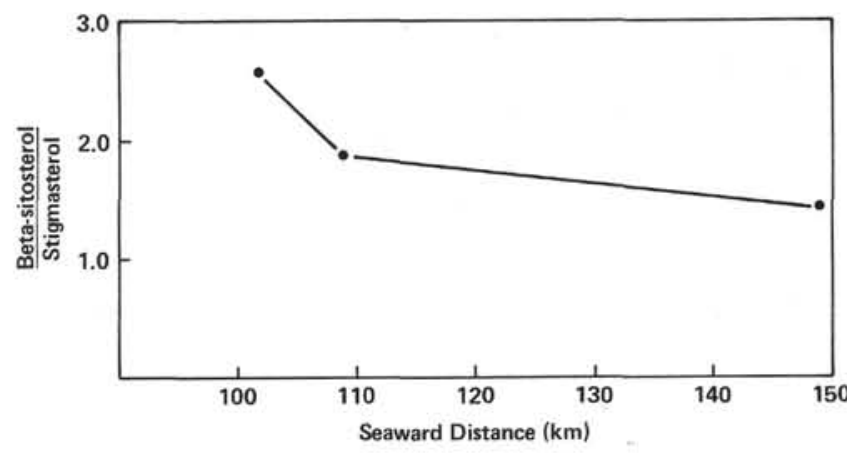

Figure 3. Beta-sitosterol/stigmasterol ratio versus seaward distance. (Data from gas chromatographic analysis of TMS-sterols in benzene fraction of the benzene-methanol extract. Chromatograph conditions: $10 \mathrm{~m}$, SP 2100 WCOT column; temperature programmed from $150^{\circ} \mathrm{C}$ [held $1 \mathrm{~min}$.] to $275^{\circ} \mathrm{C}$ [held $10 \mathrm{~min}$.] at $5^{\circ} \mathrm{C} / \mathrm{min}$.) 


\section{REFERENCES}

Attaway, D., and Parker, P. L., 1970. Sterols in Recent marine sediments. Science, 169:694-676.

Brooks, C. J. W., Henderson, W., and Steel, G., 1973. The use of trimethylsilyl ethers in the characterization of natural sterols and steroids. Characterization of natural sterols and steroid diols by gas chromatography-mass spectrometry. Biochim. Biophys. Acta, 296:431-445.

Diekmann, J., and Djerassi, C., 1967. Mass spectrometry in structural and stereochemical problems. CXXV. Mass spectrometry of some steroid trimethylsilyl ethers. J. Org. Chem., 32:1005-1012.

Eneroth, P., Hellstrom, K., and Ryhage, R., 1964. Identification and quantification of neutral fecal steroids by gas-liquid chromatography and mass spectrometry: Studies of human excretion during two dietary regimens. J. Lipid Res., 5:245-262.

Gaskell, S. J., and Eglinton, G., 1973. Short-term diagenesis of sterols. In Tissot, B., and Bienner, F. (Eds.), Advances in Organic Geochemistry: Paris (Edition Technip), pp. 963-976.

Henderson, W., Reed, W. E., and Steel, G., 1971. The origin and incorporation of organic molecules in sediments as elucidated by studies of the sedimentary sequence from a residual Pleistocene lake. In von Gaertner, H. R., and Wehner, H. (Eds.), Advances in Organic Geochemistry: New York (Pergamon Press), pp. 335-352.

Huang, W-Y., and Meinschein, W. G., 1976. Sterols as source indicators of organic materials in sediments. Geochim. Cosmochim. Acta, 40:323-330.

, 1979. Sterols as ecological indicators. Geochim. Cosmochim. Acta, 43:739-746.

Knights, B. A., 1967. Identification of plant sterols using combined GLC/mass spectrometry. J. Gas Chromatogr., 5:273-282.

Pryce, R. J., 1971. The occurrence of bound, water-soluble squalene, 4,4-dimethyl sterols, 4-alpha-methyl sterols and sterols in leaves of Kalanchoe blossfeldiana. Phytochemistry, 10:1303-1307.

Schwendinger, R. B., and Erdman, J. G., 1964. Sterols in Recent aquatic sediments. Science, 144:1575-1576.

von Huene, R., Aubouin, J., Azéma, J., Blackinton, G., Carter, J., Coulbourn, W. I., Cowan, D. S., Curiale, J. A., Dengo, C. A., Fass, R. A., Harrison, W., Hesse, R., Hussong, D., Ladd, J., Muzylev, N., Shiki, T., Thompson, P., and Westberg, J., 1980. Leg 67: The Deep Sea Drilling Project Mid-America Trench transect off Guatemala. Geol. Soc. Am. Bull., 91, Pt. 1:421-432. 